\title{
Reinforcement of aggression through intracranial stimulation'
}

\author{
THOMAS J, STACHNIK, ILLINOIS WESLEYAN UNIVERSITY \\ ROGER E, ULRICH, WESTERN MICHIGAN UNIVERSITY
}

JOHN H, MABRY, ILLINOIS WESLEYAN UNIVERSITY

Intracranial stimulation was used as a reinforcer to condition fighting in paired rats. Stimulation for an implanted animal was made contingent upon responses which successively approximated those typical of attack. A stable pattern of aggression developed, the maintenance of which was possible on intermittent reinforcement schedules although at depressed frequencies.

Electric foot shock has been used to elicit reflexive fighting in paired animals (Ulrich \& Azrin, 1962)。 Electric intracranial stimulation (ICS) has also been used to produce aggression and rage responses of a reflexive nature (Ranson, 1934; Wasman \& Flynn, 1962; Masserman, 1964). However, the use of ICS as a reinforcer for aggressive behavior has not been reported. Moreover, very few studies have conditioned aggression in paired animals according to operant principles, and those reported used food or water. Ulrich, Johnston, Richardson, \& Wolff (1963) made water reinforcement for one rat contingent upon those responses toward another rat which successively approximated attack and fighting. Fighting eventually occurred which was characteristic of unconditioned aggression. Reynolds, Catania, \& Skinner (1963) reinforced a food deprived pigeon with grain when it attacked another pigeon. A stable pattern of aggression was established and brought under the control of an exteroceptive stimulus. In the present study aggression was conditioned using ICS as the reinforcer.

\section{Method}

Bipolar electrodes were stereotaxically implanted in the posterior hypothalamus of grey-hooded rats using the following coordinates: anterior 4.4, lateral .5, depth 2.5 (DeGroot, 1959). After injection with Nembutal sodium and chloral hydrate, each $\mathrm{S}$ was implanted on a commercially available stereotaxic instrument, the nose bar of which was raised $5.0 \mathrm{~mm}$ above the interaural plane to achieve correspondence with the DeGroot Atlas. The chronic implants were attached through swivel and wiring to 100 pps bi-phasic current source monitored by an oscilloscope. The duration and programming of a pulse train of .5 sec. duration was controlled by relay apparatus located in a separate room. Three rats were used in the present study, selected from a population of implants, based on whether or not they could be trained to lever press for ICS on a continuous reinforcement schedule. The intensity of the current used was adjusted to yield maximal bar pressing rates for each $\mathrm{S}$. The experimental chamber was made of clear plastic, measured 12 by 12 by 15 in. and was housed inside a large sound proof chest. A small one-way window in the side of the chest allowed unrestricted observation. An aggressive response was recorded by an observer who depressed a microswitch following any striking or biting movements by the implant toward the head of the control animal. Reliability checks run by having different observers simultaneously record the aggression indicated that the response was well enough defined to allow accurate recording.

An implanted animal was placed in the experimental chamber with a non-operated, naive rat. The intracranial animal of each pair was given an extended sequence of "free," uncorrelated stimulation and the

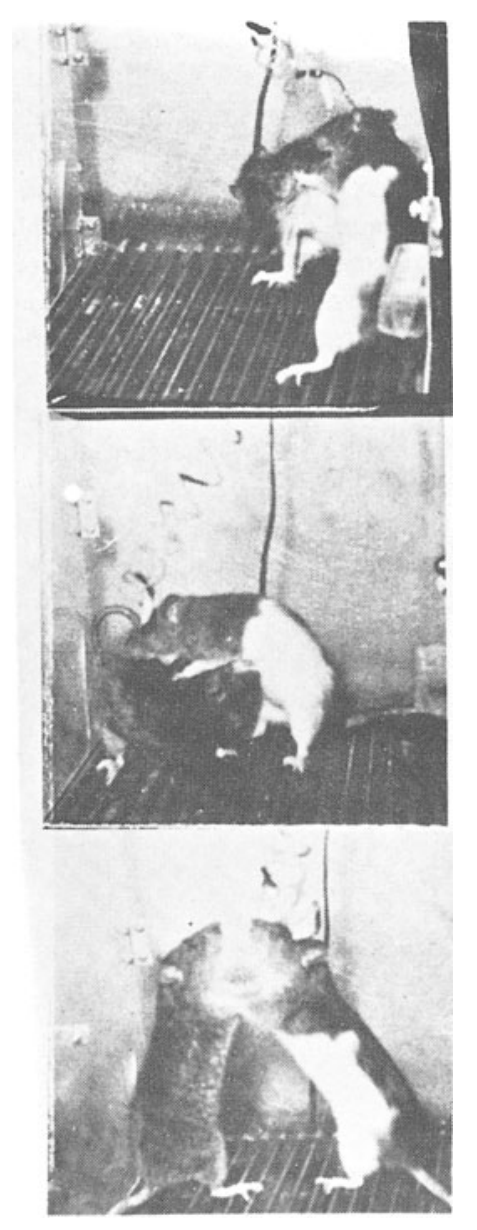

Fig. 1. Typical attack sequence showing implanted rat aggressing against a control animal. 
behavioral effect noted. This was done to determine if stimulation would elicit reflexive fighting. No fighting responses occurred. Intracranial stimulation of the same intensities and durations was then utilized to shape, by successive approximation, responses resembling attack on the second animal of each pair. After the initial shaping, striking the control animal in the area of the head and, finally, aggressive contact of two seconds was required prior to reinforcement. Once an attack response had been acquired by the implant, the animals were run for 1-hr. sessions daily. The observer recorded all attacks by depression of a microswitch which simultaneously recorded attacks and delivered intracranial stimulation.

\section{Results and Discussion}

Figure 1 is an example of an implanted rat attacking a control animal. In addition to striking and biting responses, the implanted animals frequently shoved the control animals about the chamber and often knocked them down. During this period the behavior of the control animals varied considerably. Much of the time they were extremely passive, and would often lie down and submit to the attack. At other times, however, the control animal would strike back which tended to bring both animals into the stereotyped fighting posture (bottom picture of Fig. 1) which has been consistently observed in studies of pain aggression (Ulrich \& Craine, 1964; Ulrich, Hutchinson \& Azrin, 1965). Although some characteristics of unconditioned aggression were present, the fighting observed appeared to be a function of operant reinforcement, since extinction occurred when the ICS contingency was removed.

Figure 2 summarizes the frequency of attack under both CRF and intermittent reinforcement conditions. It is readily apparent that the level of aggression observed during CRF was not maintained by the intermittent schedules. This failure to maintain the same level of aggression can perhaps be explained in two ways. One

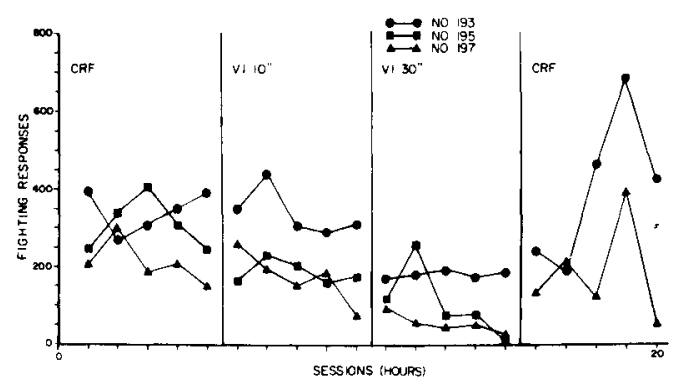

Fig. 2. Number of fighting responses per session under CRF and intermittent reinforcement conditions for the three implanted subjects. The electrode was pulled loose in \#195 following VI 30 conditions and so could not be run sessions 16-20. possibility is that our electrode placements were such that the reinforcing effects were marginal, sufficient to maintain CRF aggression but too weak to maintain either ratio of interval performance. Similar results were found with water reinforcement (Carlton, 1961) where bar pressing rate by moderately satiated rats was increased by reinstating CRF conditions following a fall off in rate on various intermittent schedules. A second possible explanation involves the relative frequencies of reinforcement and the punishment administered in the form of counter-aggression by the control animal. Since reinforcement density is lowered when an intermittent schedule is introduced while the frequency of punishment remains the same, it is not unreasonable that the frequency of attack would diminish.

The use of intracranial stimulation to reinforce aggressive behavior has an important advantage over both food and water used in previous research. The presentation of either of these conventional reinforcers following an attack response produces many intervals of no fighting, since the experimental animal terminates the fight in order to avail himself of the food or water. No such lull in fighting occurred in the present study since the consummatory activity of eating or drinking was obviated. An attack in progress when ICS was delivered proceeded without disruption. Furthermore, no satiation effects were noted. The ICS appeared to be just as effective a reinforcer after as many as $\mathbf{5 0 0}$ stimulations as at the beginning of a session.

\section{References}

Cariton, P. L. The interacting effects of deprivation and reinforcement schedule. J. exp. Anal. Behav., 1961, 4, 379-381.

DeGroot, J. The rat forebrain in stereotaxic coordinates. Verh. Kon. Ned. Akad. Wet. Naturkunde, 1959, 52, 1-40.

Masserman, J. H. Behavior and neurosis. Chicago: University of Chicago Press, 1964.

Ranson, S. W. The hypothalamus: Its significance for visceral innervation and emotional expression. Transactions of the College of Physicians of Philadelphia, 1934, 222-242.

Reynolds, G. S., Catania, A. C., \& Skinner, B. F. Conditioned and unconditioned aggression in pigeons. J. exp. Anal. Behav., $1963,1,73-75$.

Ulrich, R. E., \& Azrin, N. H. Reflexive fighting in response to aversive stimulation. J. exp. Anal. Behav., 1962, 5, 511-520.

Ulrich, R. E., Johnston, M., Richardson, J., \& Wolff, P. C. The operant conditioning of fighting behavior in rats. Psychol. Rec., $1963,13,465-470$.

Ulrich, R. E., \& Craine, W. H. Behavior: Persistence of shockinduced aggression. Science, 1964, 143, 971-973.

Ulrich, R. E., Hutchinson, R. R., \& Azrin, N. H. Pain-elicited aggression. Psychol. Rec., 1965, 15, 111-126.

Wasman, M., \& Flynn, J. Directed attack elicited from hypothalamus. Arch. of Neurol., 1962, 6, 60-67.

\section{Note}

1. This research was supported by the National Institute of Mental Health, United States Public Health Service (MH-08241) and the Psychiatric Training and Research Board of the Illinois Department of Public Welfare. The assistance of Peter Wolff. Terry Anspach, Joan Laskin, and Phyllis Thomson is gratefully acknowledged. 